\title{
Very slow creep tests on salt samples
}

\author{
P. Bérest ${ }^{\text {la }}$, J.F. Béraud ${ }^{1}$, B. Brouard ${ }^{2}$, P.A. Blum ${ }^{3}$, J.P. Charpentier ${ }^{1}$, V. de Greef $^{1}$, H. Gharbi ${ }^{1}$ and \\ F. Valès ${ }^{1}$ \\ ${ }^{1}$ LMS, Ecole Polytechnique, 91128 Palaiseau Cedex, France. \\ ${ }^{2}$ Brouard Consulting, 101 rue du Temple, 75003 Paris, France. \\ ${ }^{3}$ Institut de Physique du Globe de Paris, Jussieu, 75005 Paris, France.
}

\begin{abstract}
Long-term creep tests have been performed on rock-salt and argillite samples under very small uniaxial loadings $(\sigma=0.02$ to $0.1 \mathrm{MPa})$. To minimize the effects of temperature variations, testing devices were set in a mine where temperature fluctuations are of the order of one-hundredth of a degree Celsius. The mechanical loading was provided by dead weights. The deformations were measured through special displacement sensors with a resolution of $\Delta \varepsilon=10^{-8}$. Strain rates as small as $\dot{\varepsilon}=7 \times 10^{-13} \mathrm{~s}^{-1}$ were measured. These tests allow rock-sample creep to be investigated at very small strain rates. The tests also prove that extrapolation of constitutive laws at very small rates is often incorrect.
\end{abstract}

\section{Introduction}

The mechanical behavior of salt has given rise to abundant literature motivated by the needs of salt mining, hydrocarbon storage and, above all, nuclear waste disposal. Most authors observe that, when a constant mechanical load is applied to a salt sample, a steady-state strain rate is reached after some time; it is a non-linear function of the applied stress, and it is sensitive to temperature. The Norton-Hoff model captures the main features of such a steady-state behavior:

$$
\dot{\varepsilon}=A \exp (-Q / R T) \sigma^{n}
$$

where the constants typically belong to the $n=3-6, Q / R=3000-10,000 \mathrm{~K}$. When $\sigma=10 \mathrm{MPa}$, the steady-state strain rate typically is $\dot{\varepsilon}_{10 \mathrm{MPa}}^{\mathrm{ss}}=10^{-10} \mathrm{~s}^{-1}$. Stresses in the $\sigma<1 \mathrm{MPa}$ range are of great significance from a practical point of view, as this is the kind of deviatoric stresses which are experienced at a short distance from an underground opening. When $n=3$ is allowed, the (extrapolated) steady-state strain rate is $\dot{\varepsilon}_{0.1 \mathrm{MPa}}^{s s}=10^{-16} \mathrm{~s}^{-1}$ when the deviatoric stress is $\sigma=0.1 \mathrm{MPa}$. In fact, extrapolation cannot be supported by theoretical arguments. A deformation-mechanism map (adapted from [1]) is presented in Figure 1. The governing creep-mechanism is indicated for each domain of the Temperature-Deviatoric Stress plane; the homologous temperature is the temperature (in Kelvin) divided by salt melting temperature $(1077 \mathrm{~K})$ and $\mu$ is the shear modulus. Two rectangles also are drawn; the $\left[0-120^{\circ} \mathrm{C}\right] \times[5-20 \mathrm{MPa}]$ rectangle is the domain in which laboratory tests generally are performed. Except for the upper part of the first rectangle, in which dislocation creep is the dominant mechanism, the micro-mechanism that governs creep in these two rectangles is poorly known, and no theoretical consideration support extrapolation of empirical data to much smaller applied stresses. 


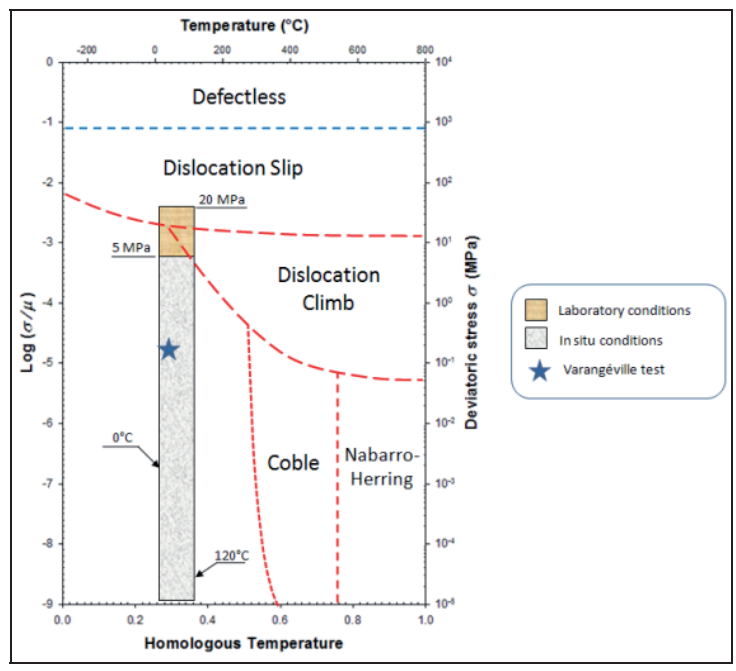

Fig. 1. Mechanism Map (after[1]).

Small strain rates $\left(\dot{\varepsilon}=10^{-14}\right.$ to $\left.10^{-11} \mathrm{~s}^{-1}\right)$ have not been investigated widely in the laboratory. Hunsche [2] describes the measurement of creep in rock salt at small strain rates using a special testing device; the test lasted approximately one week; $\left(\dot{\varepsilon}=7 \times 10^{-12} \mathrm{~s}^{-1}\right)$ was "the lowest reliably determined deformation rate" [2, p. 194].The limited available literature is probably inherent to the particular problems raised by long-term, small-rate creep tests, as noted below:

1. When the creep rate is $\left(\dot{\varepsilon}=10^{-12} \mathrm{~s}^{-1}\right)$, a test lasting 12 days results in a strain of $\left(\dot{\varepsilon}=10^{-6}\right)$. The thermal expansion coefficient of salt is $\alpha=4 \times 10^{-4}{ }^{\circ} \mathrm{C}^{-1}$ - that is, the "noise" (i.e., sample thermo-elastic deformation) due to small temperature variations will be larger, in most cases, than the signal to be measured (i.e., sample average deformation originated by creep proper). The same can be said of hygrometric variations $[3,4]$.

2. Slow creep rates are obtained when small mechanical loadings are applied. Most creep test devices are designed to operate in the deviatoric stress range of 5-20 MPa. Stress control is usually poor when the applied stress is smaller than $1 \mathrm{MPa}$.

3. Creep rate is computed by comparing the strains $\varepsilon_{1}, \varepsilon_{2}$ measured at two different times, $t_{1}$ and $t_{2}$, or $\dot{\varepsilon}=\left(\varepsilon_{2}-\varepsilon_{1}\right) /\left(t_{2}-t_{1}\right)$. When $\dot{\varepsilon}=10^{-12} \mathrm{~s}^{-1}$ and $t_{2}-t_{1}=10^{5} \mathrm{~s}$, $\varepsilon_{2}-\varepsilon_{1}=10^{-7}$ and a reasonable assessment of daily strain rate demands that strain be measured with an accuracy of at least $10^{-8}$.

In other words, accurate long-term creep tests are possible only when there is very accurate measurement of sample length change, when the applied load remains constant, and when the temperature and hygrometry experience very small changes. This paper describes such experiments 
performed in underground rooms (to take advantage of very stable temperature) using an extremely accurate sensor and dead-weight loading.

\section{Measurement system}

\section{1.Testing device}

Uniaxial creep tests were conducted on cylindrical rock samples (diameter, $D=70 \mathrm{~mm}$; height, $H=160$ $\mathrm{mm}$ ). The sample was set between two stiff silica plates (Figure 2), with a steel cap set between the sample and the upper silica plate. During each test, four high-resolution displacement sensors were set in two vertical planes at a $90^{\circ}$ angle to allow both the relative rotation of the two plates and their average relative displacement to be measured.

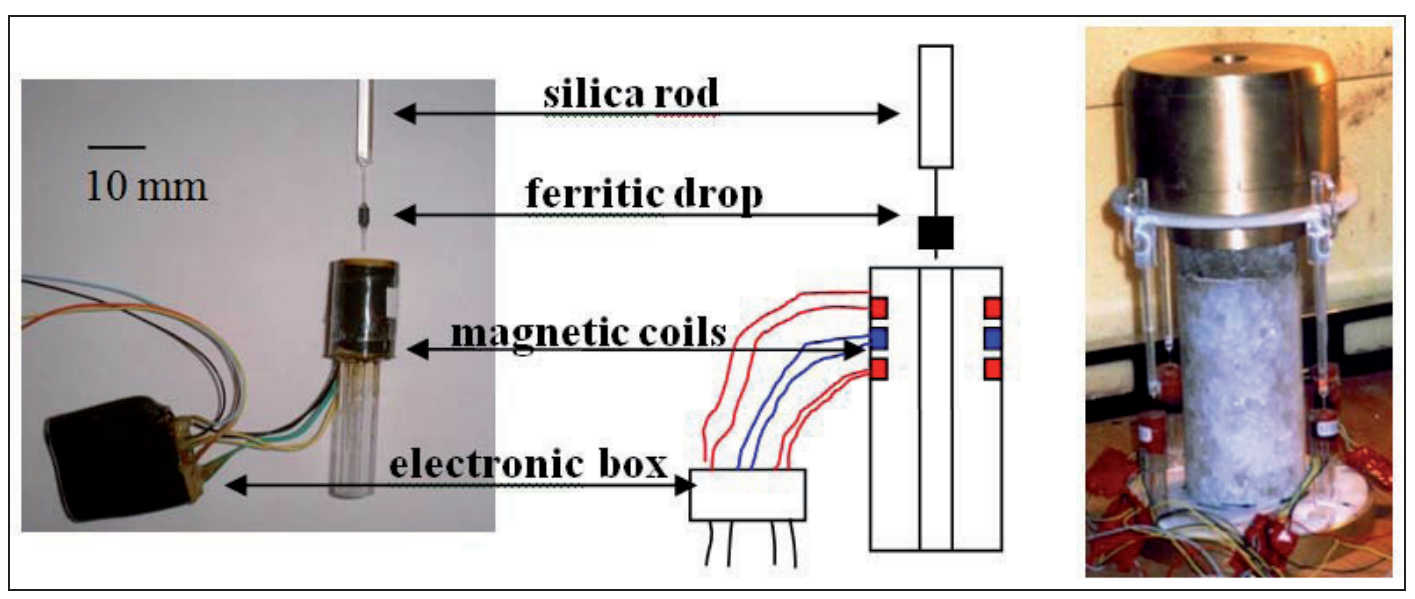

Fig.2. A sensor and a testing device.

The sensors (Figure 2) were designed by P.A. Blum. A vertical silica rod is fixed to the upper plate; at its lower tip, a silica drop encapsulates a ferritic element that moves up and down inside a vertical silica tube that bears a magnetic coil and is fixed to the lower plate. Silica is used to minimize the effects of thermal perturbations. Small displacements of the ferritic element generate voltage, which is recorded. A $1-\mu m$ displacement generates a $1-m V$ voltage. Because $1-\mu$ Volt tension can be measured easily, measurement of a $10^{-8}$ strain variation on a sample $100-\mathrm{mm}$ high can be expected.

Possible sensor drift is a concern. A two-year reference test was performed on a 10-cm-long sensor in an underground quarry (to take advantage of almost constant temperature). The upper and lower parts of a reference sensor were fixed to a rigid frame. No movement was expected. The displacement-versustime curve shows that the sensor drift was $1-\mu \mathrm{m}$ after 700 days (or 2 years), or $10^{-13} \mathrm{~s}^{-1}$, which appears as the lowest detectable strain rate using such a sensor.

To detect any purely rigid movement (rotation + vertical displacement) of the stiff upper plate, three sensors are needed. Four sensors were used during each test to provide redundancy. The results obtained from the four sensors proved to be consistent, providing confidence in sensor behaviour. For instance, light is provided by lamps that are switched on when one of the staff works in the mine gallery, and non-uniform thermal loading is generated. Reversible rotations (The displacements measured by the four sensors are not equal.) appear as soon as the lamps are switched on; they are due to the uneven heating of the lateral surface of the samples by the lamps, which induces non-homogeneous thermal expansion. However the sums of the vertical displacements of two diametrically opposed sensors remain 
equal, clear evidence of a rigid displacement and an indirect proof of sensor accuracy. However, during the course of each series of tests, one or two of the four sensors failed, either temporarily or permanently, and no further comparison was possible.

In order to keep the applied stress as constant as possible, dead weights were used. Steel cylinders were set upon the upper silica plate. The applied stress is calculated by dividing the weight of steel cylinders by the initial cross-sectional area of the sample. No attempt was made to account for the (small) diameter changes experienced during the test.

\section{2.Temperature and Hygrometry}

The temperature changes during a long-term creep test must be as small as possible, and must be measured precisely enough to allow correction of the raw strain data for thermo-elastic strains. For these reasons, the tests were performed in deep underground openings, where temperature is much more constant than in any surface facility. With the support provided by the Compagnie des Salins du Midi et Salines de l'Est, tests were performed on salt samples in a 700-m-long, 160-m-deep gallery of the Varangéville (France) salt Mine. This gallery is remote from both the area of present salt extraction and the ventilation system. Figure 3 displays temperature and hygrometry changes, continuously monitored from November 1997 (day 1) to October 1998.

Temperature, as are all other measured quantities, is recorded every two minutes during the test. The average temperature is $13.5^{\circ} \mathrm{C}$. Daily temperature variations, which are recorded with a resolution of one-thousandth of a degree Celsius, appeared to be of the order of $\pm 0.01{ }^{\circ} \mathrm{C}$. These daily variations clearly correlate to variations of atmospheric pressure. In fact, the presence of humans in the gallery, and power cuts that switch off electronic and software devices create the largest thermal perturbations. For example, temperature variations can be observed in Figure 3 (The numbers between brackets refer to Figure 3.); these occurred during scheduled operations on days 42 (1) and 203-204 (4) and, resulting from unexpected power cuts, on days 193 (3) and 297 (5). On day 133 (2), a lamp was turned on and mistakenly remained on until the lamp burned out (about 6 days later); see, also, Figure 4.

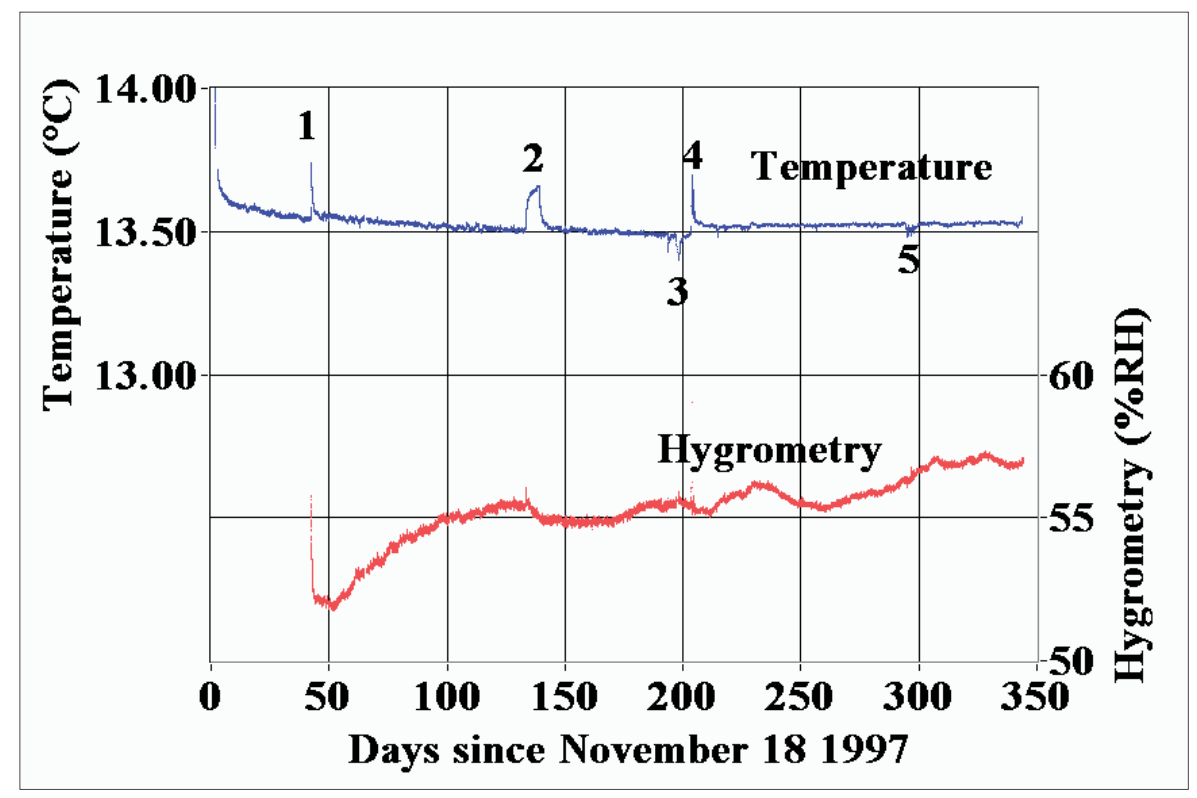

Fig. 3. Temperature and Hygrometry in the mine gallery. 


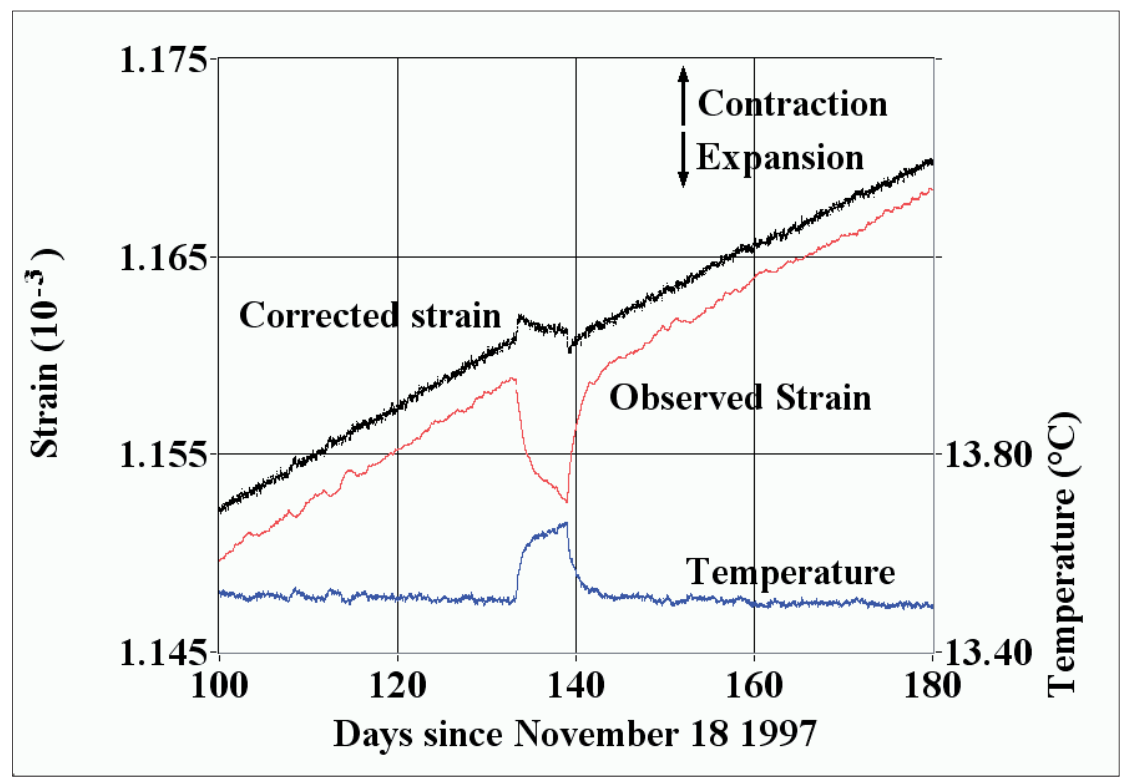

Fig. 4. As measured axial strain and temperature and corrected strain.

During the same time period, hygrometry slowly increased from $52 \% \mathrm{RH}$ to $57 \% \mathrm{RH}$, and exhibited small, long-period fluctuations. Whether these changes are actual or due to hygrometry sensor drift is difficult to assess. (Hygrometry sensor precision is not better than $\pm 2 \%$.)

\section{3 Correction for Temperature and Hygrometry}

Temperature variations generate thermo-elastic strains. A striking correlation between temperature and strain variations can be observed in Figure 4, which shows clear evidence of the thermo-elastic behaviour of rock salt. The empirical correlation coefficient is quite close to the thermal-expansion coefficient of the rock $\left(\alpha=4.4 \times 10^{-5}{ }^{\circ} \mathrm{C}^{-1}\right)$ - indirect proof of the small influence of temperature on the silica sensor length. When corrected for temperature variations, the strain-versus-time curve is much smoother (see Figure 4).

Hunsche and Schulze [4] suggest that, when uniaxial creep tests are considered, the effect of humidity be taken into account by multiplying the "standard" steady-state creep rate, or $\dot{\varepsilon}_{\mathrm{s} 0}$, by a factor $\dot{\varepsilon}_{\mathrm{s}}=\dot{\varepsilon}_{\mathrm{s} 0}[1+w \sinh (q \Phi)]$, where $\Phi$ is the relative air humidity in $\% \mathrm{RH}$, and $w$ and $q$ are two constants. During our tests, $\Phi$ varies in the range $\Phi=55 \pm 2(\% \mathrm{RH})$. If we set $\Phi_{0}=55 \% \mathrm{RH}$, we get

$$
d \dot{\varepsilon} / d \Phi=\frac{w q \cosh \left(q \Phi_{0}\right)}{1+w \sinh \left(q \Phi_{0}\right)} \dot{\varepsilon}
$$

where $q=0.1$ and $w=0.1$ [4]. If these figures are accepted, a humidity change of $1 \% \mathrm{RH}(d \Phi=1)$ leads to a relative change in creep rate: $d \dot{\varepsilon} / \dot{\varepsilon}=9 \times 10^{-2}$. Although this change is significant, we did not try to correct observed displacements for hygrometry variations, as the exact accuracy and drift of hygrometry sensors are difficult to assess. 


\section{Salt creep under small mechanical loading}

\subsection{Test \#1}

Tests were performed in the Varangéville Mine on salt samples from the Etrez salt formation. Earlier tests by Charpentier [5] and Pouya [6] were performed under standard stress levels on samples from this formation.

On November 18, 1997 (day 1), Test \#1 started on a phenoblastic salt sample initially loaded to $\sigma=0.103 \mathrm{MPa}$. The applied stress was modified twice: the initial applied stress was increased to $\sigma=0.108 \mathrm{MPa}( \pm 5 \%)$ after day $42(1)$ and then decreased to $\sigma=0.076 \mathrm{MPa}(-30 \%)$ after day 343 (4). Numbers between brackets refer to Figure 5, which displays the strain-versus-time curve; this curve averages the data provided by the 4 displacement sensors. The strain rate $(\dot{\varepsilon})$ is computed every 5 days; it is averaged for a 10-day period. Strains are corrected for temperature variations. Only the effect of a large temperature increase associated with the lamp incident (2), with the set-up (3) of Test \#2 on day 203 , and with the end of Tests \#2 and \#3 (5), remain visible. Strain experienced a long initial transient period up to day 150 , at which time the average strain rate stabilized to $\dot{\varepsilon}=1.4 \times 10^{-12} \mathrm{~s}^{-1}$ (Sample contractions are positive.), with long-period amplitude fluctuations of $\pm 20 \%$; this possibly is related to fluctuations in hygrometry.

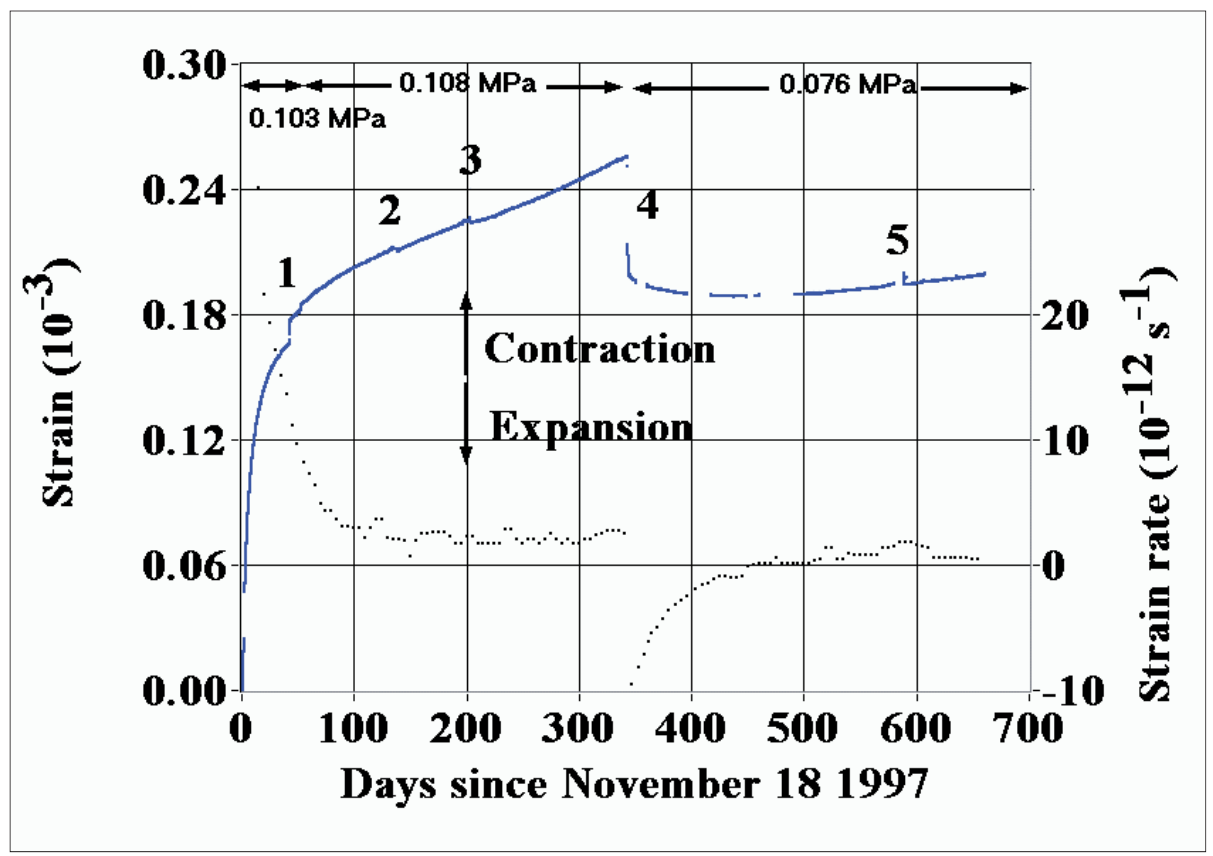

Fig. 5. Strain and strain rate during the creep test on rock sample \#1.

The $30 \%$ unloading performed on day 343 led to rapid axial expansion followed by a long period of time during which delayed axial expansion ("inverse creep") occurred. This delayed expansion can be observed up to day 450. During this period, recording was interrupted frequently due to measurement-system failures. The transient inverse creep was observed by several authors (e.g., [7], [8]). During this test, the inverse creep lasted much longer (100 days) than currently observed for tests involving larger stresses. Strain rate more-or-less stabilized after day 620 , when $\dot{\varepsilon}=7 \times 10^{-13} \mathrm{~s}^{-1}$. 


\subsection{Other tests}

On June 8, 1998 (Day 203), an identical creep apparatus was set on the same table; on day 204, Test \#2 began on a salt sample significantly purer than the former, loaded to a stress of $\sigma=0.102 \mathrm{MPa}$. In this test, creep was faster than during Test \#1: from day 100 to day 133, after the beginning of each test, the cumulated strain was $2.5 \mu \mathrm{m}$ for Test \#2 ("pure" salt) and $1.8 \mu \mathrm{m}$ for Test \#1 ("phenoblastic" salt). This difference is quite consistent with what is known from previous tests performed at larger stresses on these two salt types [6].

On October 26, 1998 (day 343), a third salt sample, of intermediate quality between pure and phenoblastic, was loaded to a stress of $\sigma=0.021 \mathrm{MPa}$ (Test \#3). No creep was observed even 177 days after the test began. The load probably was too small to generate any detectable strain. Then, the uniaxial load was increased to $0.054 \mathrm{MPa}$ by day 520 ; creep was quite slow, but measurable. A long transient period can be observed during which the creep rate progressively decreased to $\dot{\varepsilon}=1.2 \times 10^{-12} \mathrm{~s}^{-1}$.

\subsection{Comparison with tests performed under larger stresses}

Qualitatively, the behaviour of salt under small stress $(\sigma \approx 0.1 \mathrm{MPa})$ exhibits the same general features as observed under larger stresses (say, $\sigma=5$ to $20 \mathrm{MPa}$ ). Rapid stress build-up leads to transient creep characterized by a slow rate of decrease rate. Creep rate then becomes roughly constant - Steady state is reached. Loading decrease ("stress drop") generates inverse creep, which lasts much longer than during tests performed under larger compressive stresses.

For Etrez salt, Pouya [6] suggests the following parameter values for the Norton-Hoff constitutive law: $A^{*}=0.64 \mathrm{MPa}^{-\mathrm{n}} \mathrm{yr}^{-1}, Q / R=4100 \mathrm{~K}$ and $n=3.1$. If the Norton-Hoff law is extrapolated to conditions in Test \#1 $(\sigma \approx 0.108 \mathrm{MPa}, T=286.5 \mathrm{~K})$, the calculated strain rate $\left(\right.$ or $\left.\dot{\varepsilon}=10^{-17} \mathrm{~s}^{-1}\right)$ is smaller by 5 orders of magnitude than the observed strain rate $\left(\dot{\varepsilon}=1.4 \times 10^{-12} \mathrm{~s}^{-1}\right)$. The observed strain rates, even if exceedingly small, are much larger than expected. Spiers et al. [9] suggest that pressure-solution (rather than dislocation climb and glide, which are the governing mechanisms for higher stresses) is the most effective creep mechanism when very small stresses are involved; the stress exponent in this context would be $n=1$ rather than $n=3-5$, which is observed during standard tests. If this is adopted, the creep law must be modified when small stresses are considered, with significant consequences in the prediction of cavern or gallery convergence rate [10]. It is interesting to note that the measured strain rate is consistent with estimations of the Newtonian viscosity of salt $\left(\dot{\varepsilon}=A \sigma ; \eta=1 / A=10^{17} \mathrm{~Pa} . \mathrm{s}\right)$, which can be back-calculated from geological observations - e.g., the kinetics of salt-dome rise [11].

\section{Conclusions}

Long-term uniaxial creep tests were performed on rock salt samples for 650 days. The applied loads were small $(\sigma=0.02$ to $0.1 \mathrm{MPa})$. Strain rates as slow as: $7 \times 10^{-13} \mathrm{~s}^{-1}\left(2 \times 10^{-5} \mathrm{year}^{-1}\right)$ were observed in some cases. For Etrez rock salt, the qualitative results are in good agreement with what is known of rock salt behaviour under larger stresses; however, the observed strain rates, even if exceedingly small, were much larger than expected. These first test series opened the way for further investigation of rock behaviour under very small stresses, an important issue both for geological and engineering applications. 


\section{Acknowledgements}

Authors are indebted to CSME staff, MM. Hertz, Lheur and Tribou. Special thanks to Kathy Sikora.

\section{References}

[1] D.E. Munson, P.R. Dawson, Proceedings, $1^{\text {st }}$ Conference on the Mechanical Behavior of Salt, 717-738 (Trans Tech. Pub., Clausthal-Zellerfeld, Germany, 1984.

[2] U. Hunsche, Proceedings, $2^{\text {nd }}$ Conference on the Mechanical Behavior of Salt, 187-196 (Trans Tech. Pub., Clausthal-Zellerfeld, Germany, 1988).

[3] S.T. Horseman, Proceedings, $2^{\text {nd }}$ Conference on the Mechanical Behavior of Salt, 53-68 (Trans Tech. Pub., Clausthal-Zellerfeld, Germany, 1988).

[4] U. Hunsche, O. Schultze, Proceedings, $5^{\text {th }}$ Conference on the Mechanical Behavior of Salt, 73-88 (Swets \& Zeitlinger, Lisse, 2002).

[5] J.P. Charpentier, Proceedings, $2^{\text {nd }}$ Conference on the Mechanical Behavior of Salt, 131-136 (Clausthal-Zellerfeld, Germany: Trans Tech. Pub., 1988).

[6] A. Pouya, Proceedings, $32^{\text {nd }}$ US Symposium on Rock Mechanics, 385-392 (Balkema, Rotterdam, 1991).

[7] D. Munson, P. Dawson, SAD ${ }^{82}$-0962 Report, 55 p. (Sandia National Laboratories, Albuquerque, New Mexico, 1982).

[8] U. Hunsche, Proceedings, $5^{\text {th }}$ Conference on the Mechanical Behavior of Salt, 187-196 (Trans Tech. Pub., Clausthal-Zellerfeld, Germany, 1988).

[9] C.J. Spiers, J.L. Urai, G.S. Lister, Proceedings, $2^{\text {nd }}$ Conference on the Mechanical Behavior of Salt, 89-102 (Trans Tech. Pub., Clausthal-Zellerfeld, Germany, 1988).

[10] J.L. Uraï, C.J. Spiers, Proceedings, $6^{\text {th }}$ Conference on the Mechanical Behavior of Salt, 149158 (London, Taylor \& Francis Group, 2007).

[11] H. Odé, Saline Deposits, Geol. Soc. Am., 543-595 (Special Paper 88, 1968). 